\title{
BMJ
}

\section{Inability to get up after falling, subsequent time on floor, and summoning help: prospective cohort study in people over 90}

\author{
Jane Fleming, research nurse/study coordinator , Carol Brayne, professor of public health medicine, \\ and the Cambridge City over-75s Cohort (CC75C) study collaboration
}

Department of Public Health and Primary Care, University of Cambridge, Institute of Public Health, Cambridge CB2 OSR

Correspondence to: jane.fleming@phpc.cam.ac.uk carol.brayne@medschl.cam.ac.uk

Cite this as: $B M J$ 2008;337:a2227 doi:10.1136/bmj.a2227

\section{ABSTRACT}

Objectives To describe the incidence and extent of lying on the floor for a long time after being unable to get up from a fall among people aged over 90 ; to explore their use of call alarm systems in these circumstances.

Design 1 year follow-up of participants in a prospective cohort study of ageing, using fall calendars, phone calls, and visits.

Setting Participants' usual place of residence (own homes or care homes), mostly in Cambridge.

Participants 90 women and 20 men aged over $90(n=110)$, surviving participants of the Cambridge City over-75s Cohort, a population based sample.

Main outcome measures Inability to get up without help, lying on floor for a long time after falling, associated factors; availability and use of call alarm systems; participants' views on using call alarms to summon help if needed after falling.

Results In one year's intensive follow-up, 54\% (144/265) of fall reports described the participant as being found on the floor and $82 \%(217 / 265)$ of falls occurred when the person was alone. Of the $60 \%$ who fell, $80 \%(53 / 66)$ were unable to get up after at least one fall and $30 \%(20 / 66)$ had lain on the floor for an hour or more. Difficulty in getting up was consistently associated with age, reported mobility, and severe cognitive impairment. Cognition was the only characteristic that predicted lying on the floor for a long time. Lying on the floor for a long time was strongly associated with serious injuries, admission to hospital, and subsequent moves into long term care. Call alarms were widely available but were not used in most cases of falls that led to lying on the floor for a long time. Comments from older people and carers showed the complexity of issues around the use of call alarms, including perceptions of irrelevance, concerns about independence, and practical difficulties.

Conclusions Lying on the floor for a long time after falling is more common among the "oldest old" than previously thought and is associated with serious consequences. Factors indicating higher risk and comments from participants suggest practical implications. People need training in strategies to get up from the floor. Work is needed on access and activation issues for design of call alarms and information for their effective use. Care providers need better understanding of the perceptions of older people to provide acceptable support services.

\section{INTRODUCTION}

The risk of falling increases with age and declining muscle function reduces the ability to get up. If an older person is unable to get up off the floor after a fall, the attendant risks of any fall are far greater because of the complications that can ensue from lying on the floor for a long time- for example, pressure sores (often exacerbated by unavoidable incontinence), carpet burns, dehydration, hypothermia, pneumonia, and even death. ${ }^{1}$ Attending older people who have fallen is a major component of emergency service duties for ambulance crews, ${ }^{2}$ and, even for the high proportion of these people not transferred to hospital, this inability to get up has a poor prognosis in terms of the risk of injury in a subsequent fall, ${ }^{3}$ admission to hospital, ${ }^{1}$ and mortality. ${ }^{14}$ Lying on the floor for a long time is thus one of the most serious consequences of a fall, and, with population growth already fastest among the oldest old (people aged $\geq 90$ ), there is a need for population based estimates of the extent of this problem in advanced old age.

Assistive technology might have a role in the care of vulnerable people who are often alone, ${ }^{5-8}$ and devices such as call alarm systems are increasingly available to older people in the United Kingdom. A few studies in the United States have found that such personal emergency response systems might be cost effective in reducing hospital admissions, ${ }^{910}$ but uptake and adherence are low. ${ }^{112}$ In our prospective study of falls among the oldest old we sought to quantify lying on the floor a long time and explored the extent to which such alarms were used.

\section{METHODS}

Data were collected on the immediate consequences of falls among participants of a population based studythe Cambridge City over-75s Cohort (CC75C). The methods have been described in detail elsewhere for the cohort overall (www.cc75c.group.cam.ac.uk) ${ }^{13}$ and 
for its survey at year 17 , when all participants were aged over 90 , which focused on falls..$^{14} 15$

The longitudinal cohort study of older old people initially recruited participants through general practices in the 1980s, when they were all aged 75 or over. Repeated surveys since baseline have gathered data on a range of variables including sociodemographics, physical and mental health, function, and detailed cognitive assessment ${ }^{16}$ that included the mini-mental state examination. ${ }^{17}$ All those who took part in the 2002-3 survey (90 women and 20 men) were followed up in a prospective study of falls for one year or until death if sooner. We gathered details of each fall either when falls were reported by telephone or, after we received a weekly

Table 1 |Characteristics of study sample. Figures are numbers (percentages) of participants unless stated otherwise

\begin{tabular}{|c|c|c|c|c|}
\hline & $\begin{array}{l}\text { All participants } \\
\qquad(n=110)\end{array}$ & $\begin{array}{l}\text { Participants with } \geq 1 \\
\text { fall reported }(n=66)\end{array}$ & $\begin{array}{l}\text { Participants with no } \\
\text { fall reported }(n=44)\end{array}$ & $P$ value* \\
\hline \multicolumn{5}{|l|}{ Age (years): } \\
\hline Mean (SD) & $94.4(2.4)$ & $94.6(2.6)$ & $94.2(1.9)$ & 0.4 \\
\hline Median & 93.8 & 93.8 & 93.7 & - \\
\hline Interquartile range & $92.7-95.8$ & $92.7-96.0$ & $92.7-95.6$ & - \\
\hline Range & $91.6-105.8$ & $91.8-105.8$ & $91.6-99.3$ & - \\
\hline Women & $90(82)$ & $56(85)$ & $34(77)$ & 0.3 \\
\hline $\begin{array}{l}\text { Left school aged } \geq \\
15 \text { years }\end{array}$ & $43(39)$ & $28(42)$ & $15(34)$ & 0.4 \\
\hline $\begin{array}{l}\text { Non-manual social } \\
\text { class }\end{array}$ & $51(48)$ & $30(47)$ & $21(50)$ & 0.8 \\
\hline \multicolumn{5}{|l|}{ Place of residence: } \\
\hline Community & $62(56)$ & $35(53)$ & $27(61)$ & \multirow{3}{*}{0.4} \\
\hline Sheltered housing & $19(17)$ & $13(20)$ & $6(14)$ & \\
\hline $\begin{array}{l}\text { Care home/long stay } \\
\text { ward }\end{array}$ & $29(26)$ & $18(27)$ & $11(25)$ & \\
\hline \multicolumn{5}{|l|}{ Living alone: } \\
\hline Community & $43 / 62(69)$ & $26 / 35(74)$ & $17 / 27(63)$ & 0.3 \\
\hline Sheltered housing & 19/19 (100) & $13 / 13(100)$ & $6 / 6(100)$ & 0.5 \\
\hline \multicolumn{5}{|c|}{ Maximum walking distance: } \\
\hline $\begin{array}{l}\text { Unable to walk } \\
\text { around local area }\end{array}$ & $84(76)$ & $52(79)$ & $32(73)$ & 0.5 \\
\hline $\begin{array}{l}\text { Unable to walk } \\
\text { outdoors }\end{array}$ & $34(31)$ & $19(29)$ & $15(34)$ & 0.6 \\
\hline \multicolumn{5}{|l|}{ Use of walking aid: } \\
\hline Not needed outdoors & $13(12)$ & $5(8)$ & $8(18)$ & \multirow{3}{*}{0.6} \\
\hline Needed aid outdoors & $86(78)$ & $54(82)$ & $32(73)$ & \\
\hline Never goes outdoors & $11(10)$ & $7(11)$ & $4(9)$ & \\
\hline Not needed indoors & $38(35)$ & $22(33)$ & $16(36)$ & \multirow{3}{*}{0.4} \\
\hline Needed aid indoors & $71(64)$ & $44(67)$ & $27(61)$ & \\
\hline Bedridden & $1(1)$ & $0(0)$ & $1(2)$ & \\
\hline $\begin{array}{l}\text { Cannot climb stairs/«1 } \\
\text { flight/day }\end{array}$ & $72(65)$ & $47(71)$ & $25(57)$ & 0.1 \\
\hline $\begin{array}{l}\text { Severe cognitive } \\
\text { impairment } \neq\end{array}$ & $35(32)$ & $24(36)$ & $11(25)$ & 0.2 \\
\hline \multicolumn{5}{|l|}{ Falls in previous year§: } \\
\hline None recalled & $46(42)$ & $23(35)$ & $23(52)$ & \multirow{3}{*}{$<0.001$} \\
\hline 1 recalled fall & $26(24)$ & $9(15)$ & $17(39)$ & \\
\hline$\geq 2$ recalled falls & 37 (34) & $33(50)$ & $4(9)$ & \\
\hline
\end{tabular}

*For difference between participants with $\geq 1$ and no reported fall(s).

†Data missing for four, two each with and without reported falls.

¥Min-mental state examination score $0-17$ or diagnosed dementia

$\S$ Data missing for one. report on falls by post, when the project nurse made a follow-up visit or phone call. Whenever possible, information was sought both from the study participant and from any proxy informant. Data recorded after each fall included whether the individual who fell had been able to get up without help, how long they were on the floor, any injuries, and whether they called for assistance. We used the classifications of Tinetti et al to ask about needing help to rise, ${ }^{1}$ and our study protocol followed the wording and categorisation of time on the floor from Nevitt et al. ${ }^{18}$ Measurement of injuries and hospital admissions will be published elsewhere; briefly, injuries were categorised as major or minor after the widely used definitions applied in the major Scandinavian surveillance studies. ${ }^{1920}$ We classed injuries that resulted in pain for over two weeks as "serious minor injuries," according to the categorisation of Lord et al, ${ }^{21}$ and grouped them with major injuries as "serious injuries." Follow-up procedures kept track of dates and reasons for hospital admissions and discharges and for moves into long term care. We used the categorisation "severe cognitive impairment" for participants with scores $0-17$ on the mini-mental state examination or with diagnosed dementia. Terms for place of residence reflect the UK context: supported settings include "sheltered" housing schemes with live-in or visiting wardens on call as well as long term care institutions, ranging from homes providing personal care to nursing homes. We classified people "living in a house, flat, or granny flat" as "community dwelling."

\section{Analysis}

We performed analyses in Stata 9 and explored cross tabulations of descriptive data. We compared those who did or did not report falls during follow-up by examining differences in values of the continuous variable age using Student's $t$ test and differences in proportions of binary and ordered categorical variables using Pearson $\chi^{2}$ test, with Fisher's exact test where appropriate, and the score test for trend. Bivariate and multiple variable associations with not being able to get up unaided after falling and with lying on the floor for over an hour were quantified with logistic regression and with Cox regression for one time dependent variable. We adjusted crude odds ratios and hazard ratios for age, sex, and mobility using the only factor common to the different models selected by forwards and backwards stepwise regressions - climbing less than one flight of stairs a day. We recorded subjective comments of participants and relatives and coded the qualitative data from these verbatim transcripts using framework analysis methods to identify emergent themes concerning the use of call alarms and summoning help.

\section{RESULTS}

\section{Characteristics of the study sample}

Of the surviving participants from the original Cambridge study, $110(84 \%)$ took part in the falls survey and follow-up (age 91-105, median 94). Sixty six (60\%) were reported to have fallen at least once during the year after interview. ${ }^{145}$ Table 1 describes characteristics of 
these 56 women and 10 men alongside the full sample and those with no reported falls during follow-up. Participants were predominantly frail-most were unable to climb stairs, nearly a third were unable to walk outdoors, one in 10 were housebound, and about one in three were severely cognitively impaired. Fewer than half, however, were living in institutional or sheltered settings and more than a fifth were still able to walk around their local neighbourhood. Two thirds of the people living in the community lived alone, and all those in sheltered housing were in single flats. More of those who reported falling during the follow-up year tended to have worse cognitive and mobility impairment than the others, but their differences reached significance only in the history given of recalled falls in the preceding year.

\section{Falling in different residential settings}

During follow-up at least one fall was reported for $56 \%$ $(35 / 62)$ of the participants living in the community, $68 \%(13 / 19)$ of those living in sheltered housing, and $62 \%(18 / 29)$ of those in institutional settings (residential care, nursing home, or hospital) at the time of interview. There were 265 reported falls in total as most people fell at least twice. ${ }^{15}$ This was not always in the same setting as at interview as some participants who were originally in their own homes were subsequently in hospital or care homes when they fell. Falls in the community accounted for $45 \%(120 / 265)$ of all falls reported; the remaining 23\% (62/265) and 31\% $(83 / 265)$ of falls happened in sheltered housing schemes and institutional settings respectively.

\section{Falling alone}

In one year's intensive follow-up, over half (144/265, $54 \%$ ) of fall reports described the participant as being found on the floor. Table 2 shows the proportions of falls that happened when the person who fell was on their own: $82 \%(217 / 265)$ overall but as high as $94 \%$ $(58 / 62)$ in sheltered accommodation. In terms of people who fell, rather than falls, 88\% (58/66) were alone when at least one of these falls happened.

\section{Inability to get up from the floor}

Not being able to get up was equally common whether a fall was witnessed or occurred alone. Everyone who fell in an institutional setting, $(66 \%, 41 / 62)$ who fell in sheltered housing, and $(43 \%, 52 / 120)$ who fell in

Table 2 | Falls that occurred when participant was alone, inability to get up, and time on floor by place of residence. Figures are numbers (percentages) of falls by setting

\begin{tabular}{lcccc} 
& $\begin{array}{c}\text { Community } \\
(\mathrm{n}=120)\end{array}$ & $\begin{array}{c}\text { Sheltered } \\
\text { housing }(\mathrm{n}=62)\end{array}$ & $\begin{array}{c}\text { Institutional } \\
\text { settings }(\mathrm{n}=83)\end{array}$ & $\begin{array}{c}\text { All } \\
(\mathrm{n}=265)\end{array}$ \\
Alone when fell & $93(78)$ & $58(94)$ & $66(80)$ & $217(82)$ \\
\hline Needed help to get up & $52(43)$ & $41(66)$ & $83(100)$ & $176(66)$ \\
\hline Time on floor (hours) & & & & \\
\hline$<1$ & $97(81)$ & $40(65)$ & $72(87)$ & $209(79)$ \\
\hline$\geq 1$, excluding unknown & $16(13)$ & $17(27)$ & $7(8)$ & $40(15)$ \\
\hline Unknown & $7(6)$ & $5(8)$ & $4(5)$ & $16(6)$ \\
\hline
\end{tabular}

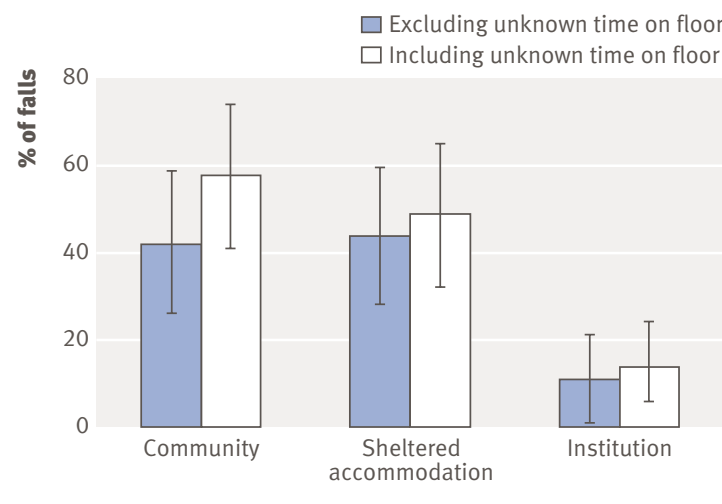

Fig 1 | Lying on the floor for over an hour after falling (143 falls in people aged $>90$ who were alone and unable to get up). Proportions with $95 \%$ confidence intervals

community settings needed help to get up after a fall (table 2). Again, considering not only the proportions of falls when this was a problem but also the proportion of people who fell who were affected, the latter was higher: in two thirds of all the falls reported the person who fell was unable to get up without help $(176 / 265$, $66 \%)$, but $80 \%(53 / 66)$ of the participants who fell had difficulty getting up from at least one fall.

\section{Lying on the floor for a long time}

Fifteen per cent $(n=40)$ of all reported falls in different settings resulted in the person lying on the floor for an hour or more (table 2). The length of time on the floor was unknown for a further $6 \%(n=16)$. When we consider people who fell, rather than falls, these proportions are even higher: $30 \%(n=20)$ of those who fell were on the floor for an hour or more on at least one occasion, and for a further $9 \%(n=6)$ the maximum time was unknown (data not tabulated).

The length of time on the floor after falling depended both on ability to get up after falling and on whether there was any help at hand. Table 3 details reported time on the floor for all falls, falls with no one present, falls when help was needed to get up, and falls when such help was needed but no one was there at the time of the fall. Increasing proportions of falls led to longer times on the floor across each of these categories. While $43 \%(114 / 265)$ of all falls led to five minutes or less on the floor, those who needed help to get up were helped up in less than five minutes in just a quarter of these falls $(46 / 176,26 \%)$, and for those who were alone when they fell and could not get off the floor, assistance to help them up arrived in less than five minutes for only $17 \%$ $(25 / 143)$ of such falls. Even if the person who fell was not alone when the fall happened, those who could not get up unaided could be on the floor for a considerable time because of the difficulty those present had in helping them up: in 10 such cases this took between five minutes and an hour.

All the incidents in which people lay on the floor for over an hour arose from unwitnessed falls, and 28\% (40/143) of unwitnessed falls led to the person lying on the floor for an hour or more. This proportion rose to over a third when we included falls with unknown floor 
times. This overall 35\% (50/143), which includes relatively few cases of a long time lying on the floor in care homes, is far lower than the high prevalence in such situations among residents in sheltered housing (44-49\% excluding or including lying on floor for unknown time) and participants living in the community $(42-56 \%)$ (fig 1).

Factors associated with inability to get up and lying on the floor for a long time

Table 4 describes the participants who were unable to get up after a fall $(\mathrm{n}=53)$, those who were on the floor for at least an hour $(n=20)$ on at least one occasion during the follow-up year, and the prevalence of injury, admission to hospital, and admission to long term care. Injuries can be both a cause and a result of lying on the floor for a long time, which can be viewed not only as a possible outcome of falling but also as a predictor of further sequelae such as admissions to hospital and care home. Table 4 shows the associations found between all these factors - descriptive characteristics and potential longer term sequelae-and the two possible results of falling detailed above - being unable to get up again without help and consequently remaining on the floor for over an hour.

Univariate analyses showed that many factors were associated with difficulty in rising from the floor, the important sociodemographic descriptors being age, sex, and residential status. Women were six times more likely than men to have difficulty getting up. Residents of any supported living setting - such as sheltered accommodation, residential care, or nursing homes — had a 16-fold increased odds of being unable to get off the floor without help; no one who fell in a care home was able to get up unaided (data not shown). Those who lived alone in the community or in sheltered housing were particularly unlikely to be able to get up after falling: the almost fivefold crude odds doubled to an adjusted odds ratio over 10. Reported mobility was consistently associated with inability to get up, limited walking distance, and the need for walking aids, conferring about fourfold to eightfold increased odds, and the odds ratio doubled again to 16 -fold for climbing less than a flight of stairs a day or being unable to manage stairs at all. Regression modelling identified this mobility descriptor as the most consistent predictor for this serious consequence of falls, outweighing the effects of cognitive impairment and recalled falls in adjusted models. Exclusion from reported mobility analyses of those who cannot walk at all had no effect on the significance of risk estimates for either outcome.

Severe cognitive impairment was highly significantly associated with lying on the floor for a long time and, unlike the reduction of effect in relation to getting up unaided, adjustment for mobility, age, and sex strengthened this finding: adjusted odds ratio 8.1 (95\% confidence interval 2.1 to 31.0 ). Living alone quadrupled the odds of lying on the floor for a long time but, with wide confidence intervals from the smaller sample in this analysis, even the higher adjusted estimate did not reach significance: 5.9 (0.5 to 77.6). No other descriptive characteristics predicted the length of time on the floor.

There were marked associations with other potential sequelae of falling for both being unable to get up and for lying on the floor for a long time. Any degree of injury was common, regardless of time on the floor, and increased the crude odds of needing help to get up fivefold, though this was not a significant factor after adjustment. Serious injury, however, was consistently associated with lying on the floor for a long time, regardless of adjustment. Of the 20 people who were reported to be on the floor over an hour after falling, 60\% (12) had a fall related hospital admission during the follow-up year (4.0, 1.3 to 12.3). Twenty nine per cent of those who had been unable to get up from the floor (11/ 38) moved into long term care within a year of interview and $39 \%(15 / 38)$ by the end of study censoring. The equivalent figures for those who remained on the floor for over an hour were 36\% (5/14) and 53\% (8/15), giving a threefold increased odds of admission to a care home, though the risk estimate did not reach significance in this smaller sample ( $\mathrm{n}=51$ not living in care who fell) until the censoring, conducted when everyone had completed their year since interview (crude hazard ratio 3.4 (1.2 to 9.5), adjusted 2.3 (0.8 to 7.0$)$ ).

Use of call alarm systems to summon help

Many of those in the study population had call alarm systems. About a third each had either a personal alarm linked to a call centre when activated, usually a pendant, or call bells installed in their room or flat (everyone in a care home and most in sheltered schemes), and 12\% (13) had both. Table 5 shows the variation across different residential settings. Of those living alone in the community or sheltered accommodation, 70\% (57/81) had some form of call alarm.

In $95 \%(209 / 219)$ of falls that occurred when the individual was alone, and in $99 \%(141 / 143)$ of falls in

\begin{tabular}{|c|c|c|c|c|}
\hline & $\begin{array}{l}\text { All falls } \\
(n=265)\end{array}$ & $\begin{array}{l}\text { Participant alone } \\
\qquad(n=217)\end{array}$ & $\begin{array}{l}\text { Participant unable to get } \\
\text { up without help }(n=176)\end{array}$ & $\begin{array}{l}\text { Participant alone and unable to } \\
\text { get up without help }(n=143)\end{array}$ \\
\hline$<5$ minutes & $114(43)$ & $78(36)$ & $46(26)$ & $25(17)$ \\
\hline 5 minutes $-<1$ hour & $95(36)$ & $85(39)$ & $78(44)$ & $68(48)$ \\
\hline 1-2 hours & $14(5)$ & $14(6)$ & $14(8)$ & $14(10)$ \\
\hline$>2$ hours & $26(10)$ & $26(12)$ & $26(15)$ & $26(18)$ \\
\hline Unknown & $16(6)$ & $14(7)$ & $12(7)$ & $10(7)$ \\
\hline
\end{tabular}


those who could not get up when they fell alone, the person had some form of call alarm system. In $80 \%$ $(113 / 141)$ of these falls, however, the person who fell alone did not use their call alarm to summon help. This was most often the case in institutional settings $(94 \%$, $62 / 66$ ) but was also so for most falls both in the community $(78 \%, 28 / 36)$ and in sheltered accommodation $(59 \%, 23 / 39)$. Of these 141 falls, 38 resulted in lying on the floor for over an hour, despite an installed alarm system, and in $97 \%$ of these "long lies" (37/38) the person who fell alone did not use their alarm to summon help.

Figure 2 shows the relation between summoning help and the length of time on the floor. Lying on the floor for an hour or more occurred in only one or perhaps two out of the 28 falls in which a call alarm was activated by someone unable to rise when they fell on their own. One arose from a resident in a care home taking over an hour to crawl round her bed to reach the call bell after falling as she got out of bed. In the other case, the only incident known to involve alcohol, the time on the floor could not be established but the mobile warden team who answered the call presumed it was a long time.

\section{Factors influencing use of call alarms}

Several themes emerged from analysis of comments made by participants and carers about why call alarms

Table $4 \mid$ Factors associated with inability to get up and lying on the floor for over an hour after falling, with unadjusted and adjusted odds ratios (95\% confidence intervals)

\begin{tabular}{|c|c|c|c|c|c|c|}
\hline & \multicolumn{3}{|c|}{ Unable to get up without help after $\geq 1$ fall } & \multicolumn{3}{|c|}{ Lying on floor for at least 1 hour after $\geq 1$ fall } \\
\hline & $\begin{array}{l}\text { No of participants } \\
\qquad(n=53)\end{array}$ & $\begin{array}{l}\text { Unadjusted } \\
(95 \% \mathrm{Cl})\end{array}$ & $\begin{array}{l}\text { Adjusted* } \\
(95 \% \mathrm{Cl})\end{array}$ & $\begin{array}{l}\text { No of participants } \\
\qquad(n=20)\end{array}$ & $\begin{array}{l}\text { Unadjusted } \\
(95 \% \mathrm{Cl})\end{array}$ & $\begin{array}{l}\text { Adjusted* } \\
(95 \% \mathrm{Cl})\end{array}$ \\
\hline Mean (SD) age (years) & $94.9(2.8)$ & & & $94.5(1.9)$ & & \\
\hline For each additional year of age & - & $1.4(1.0$ to 2.1$)$ & 1.7 (1.0 to 2.8$)$ & - & $1.0(0.8$ to 1.2$)$ & 1.0 (0.8 to 1.2$)$ \\
\hline Women $v$ men & $48(91)$ & $6.0(1.4$ to 25.5$)$ & $2.5(0.4$ to 15.6$)$ & $18(90)$ & 1.9 (0.4 to 9.8$)$ & $1.5(0.3$ to 8.7$)$ \\
\hline Left school aged $\geq 15 v \leq 14$ & $21(40)$ & $0.6(0.2$ to 1.9$)$ & $0.4(0.1$ to 2.0$)$ & $8(20)$ & 0.9 (0.3 to 2.5$)$ & $0.9(0.3$ to 2.6$)$ \\
\hline Non-manual $v$ manual social class $†$ & $23(45)$ & $0.7(0.2$ to 2.4$)$ & $0.5(0.1$ to 2.3$)$ & $11(55)$ & $1.6(0.6$ to 4.7$)$ & $1.6(0.6$ to 4.8$)$ \\
\hline \multicolumn{7}{|l|}{ Place of residence: } \\
\hline $\begin{array}{l}\text { Supported setting (sheltered/institution) } v \\
\text { community }\end{array}$ & $30(57)$ & 15.7 (1.9 to 129.0$)$ & $7.1(0.6$ to 76.1$)$ & $10(50)$ & $1.2(0.4$ to 3.4$)$ & $0.9(0.3$ to 3.0$)$ \\
\hline $\begin{array}{l}\text { Living alone } v \text { with spouse/other family (excluding } \\
\text { institutions) }\end{array}$ & $31 / 35(89)$ & 4.8 (1.1 to 22.3$)$ & 10.1 (1.0 to 99.0$)$ & $13 / 14(93)$ & $4.0(0.5$ to 35.5$)$ & $5.9(0.5$ to 77.6$)$ \\
\hline \multicolumn{7}{|l|}{ Maximum walking distance: } \\
\hline Unable $v$ unable to walk around local area & $46(87)$ & 7.7 (2.0 to 29.6$)$ & $5.0(1.0$ to 26.7$)$ & $18(90)$ & $3.2(0.6$ to 15.8$)$ & $3.0(0.6$ to 15.9$)$ \\
\hline Unable $v$ unable to walk outdoors & $18(34)$ & $6.2(0.7$ to 51.3$)$ & $3.7(0.2$ to 68.6$)$ & $4(20)$ & 0.5 (0.2 to 1.8$)$ & $0.4(0.1$ to 1.5$)$ \\
\hline \multicolumn{7}{|l|}{ Use of walking aid: } \\
\hline $\begin{array}{l}\text { Needed } v \text { not needed outdoors (excluding unable to } \\
\text { walk outdoors) }\end{array}$ & $44 / 46(96)$ & $6.6(1.0$ to 44.9$)$ & $2.4(0.2$ to 23.6$)$ & $17 / 18(94)$ & $1.8(0.2$ to 17.7$)$ & $1.4(0.1$ to 15.5$)$ \\
\hline Needed $v$ not needed indoors & $39(74)$ & 4.5 (1.3 to 15.9$)$ & 1.7 (0.3 to 8.7$)$ & $16(80)$ & $2.6(0.7$ to 8.9$)$ & 2.6 (0.6 to 10.3$)$ \\
\hline Cannot climb stairs or $<1 v \geq 1$ flight/day & $44(83)$ & $16.3(3.7$ to 71.3$)$ & $16.6(3.1$ to 87.7$)$ & $16(80)$ & $1.9(0.6$ to 6.8$)$ & $1.7(0.5$ to 6.7$)$ \\
\hline $\begin{array}{l}\text { Severe cognitive impairment } \neq v \text { moderate/no } \\
\text { impairment }\end{array}$ & $23(43)$ & $9.2(1.1$ to 76.0$)$ & 4.1 (0.4 to 46.3$)$ & $13(65)$ & $5.9(1.9$ to 18.5$)$ & 8.1 (2.1 to 31.0$)$ \\
\hline \multicolumn{7}{|l|}{ Recalled falls in past year§: } \\
\hline$\geq 1 v$ none & $37(71)$ & 3.9 (1.1 to 14.0$)$ & 2.7 (0.5 to 13.9$)$ & $13(65)$ & $1.0(0.3$ to 3.1$)$ & 0.9 (0.3 to 2.9$)$ \\
\hline$\geq 2 v$ none & $31(60)$ & 8.3 (1.6 to 43.8$)$ & $5.3(0.6$ to 44.6$)$ & $11(55)$ & 1.1 (0.4 to 3.6$)$ & $1.0(0.3$ to 3.5$)$ \\
\hline \multicolumn{7}{|l|}{ Injuries sustained in falling: } \\
\hline Any $v$ none & $40(75)$ & 4.9 (1.4 to 17.7$)$ & $3.0(0.6$ to 14.6$)$ & $17(85)$ & 3.6 (0.9 to 14.2$)$ & 3.5 (0.9 to 14.4$)$ \\
\hline Serious $v$ non-serious/none & $13(25)$ & 3.9 (0.5 to 32.9) & $3.2(0.3$ to 42.7$)$ & $8(40)$ & $4.4(1.3$ to 15.4$)$ & 4.2 (1.2 to 14.8$)$ \\
\hline Serious $v$ none (excluding non-serious) & & $8.0(0.9$ to 73.4$)$ & 6.6 (03. to 170.8$)$ & & 8.0 (1.6 to 40.3$)$ & 7.4 (1.3 to 41.1$)$ \\
\hline \multicolumn{7}{|l|}{ Hospital admissions: } \\
\hline All cause hospital admission $v$ no admission & $31(59)$ & 7.8 (1.6 to 38.5$)$ & $17.9(2.3$ to 140.3$)$ & $13(65)$ & $2.4(0.8$ to 7.2$)$ & $2.4(0.8$ to 7.3$)$ \\
\hline $\begin{array}{l}\text { Fall related hospital admission } v \text { no fall related } \\
\text { admission }\end{array}$ & $24(45)$ & $9.9(1.2$ to 82.0$)$ & $21.1(1.9$ to 230.5$)$ & $12(60)$ & 3.8 (1.3 to 11.5$)$ & $4.0(1.3$ to 12.3$)$ \\
\hline \multicolumn{7}{|l|}{ Moving to institutional care ${ }^{\star \star}$ : } \\
\hline Moved into care within 1 year $v$ not moved into care & $11 / 38(29)$ & -十† & -十† & $5 / 14(36)$ & $2.9(0.7$ to 11.6$)$ & $2.4(0.5$ to 11.0$)$ \\
\hline Moved into care by study end censoring $v$ not moved & $15 / 38(39)$ & -十† & -†† & $8 / 15(53)$ & $3.4 \neq \ddagger(1.2$ to 9.5$)$ & $2.3 \ddagger \ddagger(0.8$ to 7.0$)$ \\
\hline \multicolumn{7}{|c|}{ 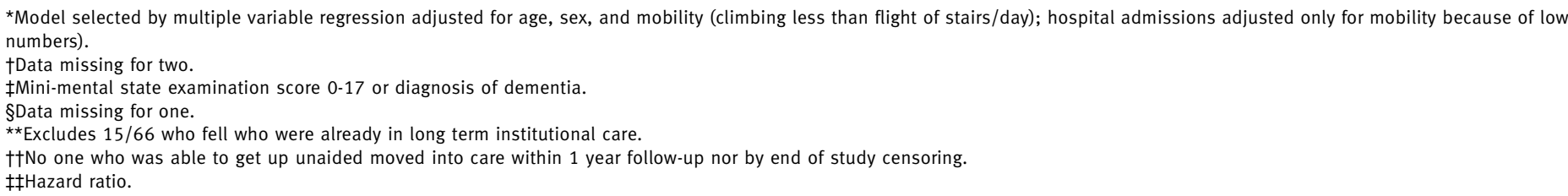 } \\
\hline
\end{tabular}


were not used. The box provides examples illustrating the range of their attitudes and abbreviated scenarios describing how the person quoted coped when they did not call for help. Barriers to using alarms arose at several crucial stages: not seeing any advantage in having such a system, not developing the habit of wearing the pendant even if the system was installed, and, in the event of a fall, not activating the alarmeither as a conscious decision or as a failed attempt.

\section{DISCUSSION}

Study summary

In this intensive follow-up of a full survey sample from a population based study of very old people, we found high rates of serious consequences of falling - being unable to get up and thus lying on the floor for a long time, the latter strongly associated with cognitive

\section{Attitudes towards the use of call alarms to summon help}

\section{Not having a call alarm}

"My niece is only next door. I can bang on the wall if I need to call help."

Daughter's comments: "She refuses to have a call alarm because she thinks it would keep going off by mistake. She is worried enough about the string pull alarms in each room [sheltered housing scheme] and often won't turn on the kitchen or bathroom lights in case she pulls the wrong cord by mistake."

\section{Having one but not wearing it}

"I have got one but I don't have to wear it yet, I just hang it on the back of the chair there." “I wasn't wearing my pendant. I don't usually wear it ... It was quite a struggle to get up. It took about half an hour. My sister pushed me across to the sofabed and we used that to help get me up ... l've been thinking after you asked last time, maybe I should wear it when my sister is out."

"I'd already taken it off ready for bed and put it on the bedside table so then I couldn't reach it." [Lost balance getting undressed, was on the floor all night until next morning finally attracted the attention of someone delivering a newspaper by calling through the doorbell intercom]

\section{Wearing but choosing not to use it}

"I wanted to be able to get up by myself. It took me a long time to get up but I did it in the end. It makes me annoyed if I have to have help." [Fell bending down to pick up a letter at the door]

"I didn't want to use the call alarm, although I was wearing it, for fear of being taken into hospital." [Trying to stand up from the toilet, fell on her back] "I grabbed the portable arms round the loo when I lost balance but they tilted. It took quarter of an hour to shuffle from the bathroom through to the sitting-room so I could pull myself up on an armchair."

"Didn't need to." [He stood up from a stool after washing his feet in a bowl on the floor and fell backwards. Difficult getting up_pulling himself up by the sink he fell backwards again, but still didn't use his call alarm]

\section{Difficulty in activating alarm}

"I couldn't have reached the alarm ... like, well, I've got the frame but I can't always reach it." [Fell trying to get from bed to commode while in hospital]

"I tried to call Care Call but the pendant didn't work because there'd been a power cut the day before." [The trolley he was walking with tipped up and he went over too, got himself across floor to climb up on to armchair in about 10 minutes, then waited a couple of hours for his carer to come]

"I was wearing my alarm but I didn't think it would work out there in the street so I didn't even try it." [Lost balance at the gate, fell on pavement outside her flat] "I sat at the kerb trying to get up but I couldn't. After what seemed like ages a car came by and a man wound down his window to ask if I was okay. He helped me up and back indoors."

"It always seems a long time when you're waiting but I don't suppose it was really." [Found on floor by carer, confused. She had not set off the alarm, although she thought she had)

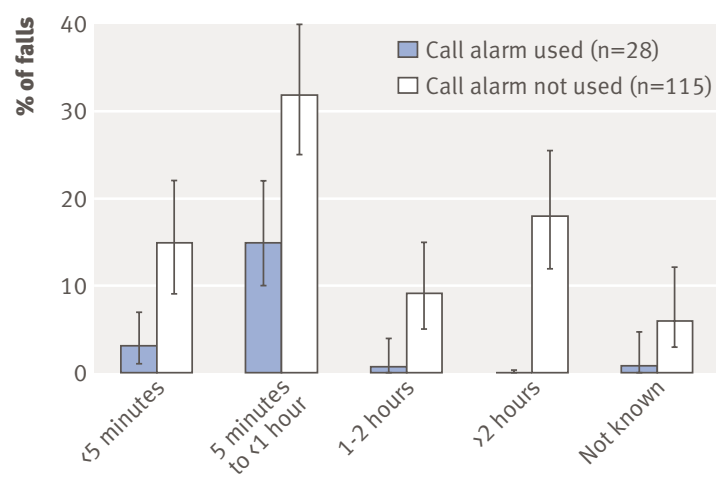

Fig 2 | Time on floor according to use of call alarm (143 falls in people aged $>90$ who were alone and unable to get up). Proportions with $95 \%$ confidence intervals

impairment. Lying on the floor for over an hour was also strongly associated with serious injuries, admissions to hospital, and subsequent moves into long term care. Call alarm systems were widely available but were often not used when they could have been. Virtually no one who did use an alarm lay more than an hour on the floor, yet nearly all (97\%) of those who lay on the floor for a long time and had a call alarm system did not activate it. The findings contribute new insights to falls research from a year's prospective data gathered specifically from people of advanced age $(\geq 90)$, including men and women living in the community and in supported or institutional settings. The comments of these older old people add a further important element to the findings: their subjective perspective on calling help after falling.

\section{Limitations}

Falls research inevitably faces considerable methodological issues concerning reliable ascertainment, and even in this prospective data collection we had to rely on recall to some extent. None the less, we aimed to maximise validity of the data by deliberately using a combination of methods-participant and proxy reports by calendar, phone calls, and visiting - and achieved remarkably complete data concerning the immediate sequelae of each fall. Despite the high incidence of unwitnessed falls, there was little scope for misreporting the proportion of people unable to get up from the floor unaided, one of the key outcomes in this paper, as these people were by definition still on the floor when help arrived. Length of time on the floor is a less robust measure, for various reasons perhaps overestimated or underestimated by anyone who fell, but possibly also under-reported by proxy informants. As most reports of such falls were provided by carers, the overall effect of any such measurement error is likely to be an underestimate of the extent of this problem.

Some caution is warranted in interpreting the analyses of association between risk factors and these consequences of falling; lack of association might indicate only the limited power of the small sample size. We used a descriptive epidemiological approach 
Table $5 \mid$ Access to call alarm systems in different residential settings. Figures are numbers (percentages) of participants

\begin{tabular}{lcccc} 
& $\begin{array}{c}\text { Community } \\
\text { dwelling }(\mathrm{n}=62)\end{array}$ & $\begin{array}{c}\text { Sheltered } \\
\text { housing }(\mathrm{n}=19)\end{array}$ & $\begin{array}{c}\text { Institutional } \\
\text { care }(\mathrm{n}=29)\end{array}$ & $\begin{array}{c}\text { All } \\
(\mathrm{n}=110)\end{array}$ \\
None & $24(39)$ & 0 & 0 & $24(22)$ \\
\hline Personal call alarm system & $36(58)$ & $2(11)$ & 0 & $38(36)$ \\
\hline Call bell in flat/room/by bed & $1(2)$ & $5(26)$ & $29(100)$ & $35(32)$ \\
\hline Both systems & $1(2)$ & $12(63)$ & 0 & $13(12)$ \\
\hline
\end{tabular}

examining a range of factors to supplement the dearth of data concerning falls in this age group, as even this small study outnumbers the oldest old subgroups enumerated in previous reports.

\section{Key findings in context}

Four out of five people who fell were unable to get up without help on at least one occasion. This far exceeds reported levels of difficulty regarding people in their $60 \mathrm{~s}, 70 \mathrm{~s}$, or even $80 \mathrm{~s}$, in which up to a quarter could not manage to get up in clinic test situations ${ }^{32223}$ and between a third to a half could not when they fell in the community. ${ }^{1418}$

Prospective data in our study showed that about a third of those people who couldn't get up after a fall were on the floor over an hour. The proportion of all falls during follow-up in which this occurred was lower - one in five -but was over a third if the person who fell was alone and could not get up without help. For falls in the community and sheltered housing this proportion was around half. These figures are again far higher than previously reported from younger people. In a UK survey in general practice $16 \%$ of those aged over 65 who fell in their own homes lay on the floor for more than an hour. ${ }^{4}$ A US community based study of those aged over 60 who had previously fallen found that one in 10 falls left the faller unable to get up for at least five minutes ${ }^{24}$ and even lower rates have been reported for different time periods. ${ }^{25}$ In institutional settings, we found lying on the floor for a long time was less common.

\section{Implications}

These important findings support an earlier call to include teaching older people how to get up if they fall in preventive initiatives. ${ }^{26}$ Recalled falls and reported limitations with mobility were strongly associated with being unable to get up after falling, suggesting that taking a simple clinical history could help to identify those who might benefit. Such training is rare, despite growing evidence for its effectiveness, ${ }^{327-29}$ including good evidence from trials for using floor rise training in tailored exercise programmes for fall prevention. ${ }^{29}$

Cognitive impairment was the only characteristic that predicted lying on the floor for a long time, probably indicating that the most cognitively impaired are the least likely to summon help when they cannot get up. This finding, in addition to the known increased risk of falling in cognitively impaired elderly people, supports the argument for more work in this challenging area. ${ }^{30}$ The development of automatic fall detectors that do not rely on the wearer activating them ${ }^{8}$ could help to reduce time on the floor for this vulnerable group.

While difficulty in getting up from the floor is more likely in people in supported living, a finding that would be expected, it is interesting to note that the odds of lying on the floor for a long time were not reduced by the additional level of care. This finding might seem contrary to the results in table 2 , which show that most institutional falls led to less than an hour on the floor; the odds ratio in table 4 , however, reflects instead the proportion of individuals affected rather than falls. Moreover, this analysis grouped those in care homes with people living in sheltered housing, where lying on the floor for over an hour was as common as in the community. Calling for help can still be problematic in institutional settings: the policy occasionally seen of encouraging residents to wear personal alarms in addition to room call bell systems might have a role to play, and the use of video cameras, as introduced in some US care homes, highlights how technological solutions can raise important ethical questions about the balance between privacy, dignity, safety, and the duty of care. Tele-care solutions, however, should not be viewed as a substitute for hands-on care; one possible strategy to reduce the risk of people lying on the floor for a long time after a fall in care homes might be more frequent checking of residents with dementia.

The fact that nearly all people who couldn't get up had access to a call alarm system but did not use it to summon help raises important questions for care providers. Only a few studies to date have explored older people's views on assistive technology devices, ${ }^{1112}$ some reporting overall positive attitudes, ${ }^{6}$ including specific mention that fall alarms improve confidence, ${ }^{7}$ but there have been studies examining reluctance to seek or accept help. ${ }^{31}$ The findings from recent research exploring attitudes to falls prevention are also pertinent: older people are understandably reluctant to be labelled as at high risk for falling. ${ }^{323}$ The emergent themes in this study include older people's justifiable concern to preserve their independence,

\section{WHAT IS ALREADY KNOWN ON THIS TOPIC}

Being unable to get up after falling can have serious consequences for an old person, especially if they are on the floor a long time

\section{WHAT THIS STUDY ADDS}

Being unable to get up and therefore lying on the floor for a long time are highly prevalent after falls among men and women aged over 90

Severe cognitive impairment was the only intrinsic factor predicting lying on the floor for a long time

Lying on the floor for a long time after a fall was associated with repeated falls, fall induced injuries, and subsequent admissions to hospital and long term care

Alarm systems were widely available but rarely used to call for help to get up 
both in immediate terms - for example, wanting to get up unassisted - and in terms of the longer view-for example, wanting to avoid admission to hospital. Among those who did not have or did not wear any personal alarm, such devices were not perceived as relevant, usually synonymous with a view that falling was unlikely, a self perception that has been reported in other high risk groups, ${ }^{3435}$ and similar attitudes have been reported to the use of hip protectors. ${ }^{36}$ There are practical implications for provision of information and training arising from the comments from some of the frailer individuals who tried unsuccessfully to use their alarms, such as ensuring users can actually activate the devices and are aware of their signal range.

Comments from study participants and their relatives revealed pertinent concerns on which further qualitative research might shed more light, particularly to inform the development of interventions to reduce the length of time people lie on the floor after a fall, including the design of call or detector systems. These are complex issues that care providers need to understand better so as to offer and effectively deliver support services and devices that are acceptable to the older people concerned.

We gratefully acknowledge the contributions of previous investigators and past research team members (see www.cc75c.group.cam.ac.uk/ pages/studypersonnel), collaborating general practitioners and their practice teams, and, most particularly, the study respondents, their families and friends, and the staff in many care homes. Rosemary Abbott, Stephen Barclay, Tom Dening, Morag Farquhar, Felicia Huppert, AnnLouise Kinmonth, Fiona Matthews, Elizabeta Mukaetova-Ladinska, Graciela Muniz, Angela O'Sullivan, Eugene Paykel, Kathryn Richardson, and Emily Zhao (current CC75C collaborators) commented on earlier drafts of this paper

Contributors: CB (with Tom Dening, Felicia Huppert, and Eugene Paykel) contributed to the development of the cohort study overall. JF, under CB's supervision, helped to develop the protocol for the falls study follow-up survey of the cohort, conducted all the interviews for this wave and the prospective falls data collection, analysed the data, and wrote the original manuscript draft. Both authors are guarantors.

Funders: This study was supported by an NHS executive research and development unit health services research fellowship and CC75C is currently supported by the BUPA Foundation. No funders (see www. cc75c.group.cam.ac.uk/pages/grant for full list) had any role in the study design, analysis, or writing of this paper.

Competing interests: None declared.

Ethical approval: For each participant written informed consent was obtained either in person or from the proxy informant, as approved by Cambridge research ethics committee.

Provenance and peer review: Not commissioned; externally peer reviewed.

1 Tinetti ME, Liu WL, Claus EB. Predictors and prognosis of inability to get up after falls among elderly persons. JAMA 1993;269:65-70.

2 Halter M, Close J, Elrick A, Brain G, Swift C. Falls in the older population: a pilot study to assess those individuals who are attended to by the London ambulance service as a result of a fall but are not conveyed to hospital. London: London Ambulance Service NHS Trust Report, 2000.

3 Bergland A, Laake K. Concurrent and predictive validity of "getting up from lying on the floor". Aging Clin Exp Res 2005;17:181-5.

4 Wild D, Nayak US, Isaacs B. How dangerous are falls in old people at home? BMJ 1981;282:266-8.

5 Miskelly FG. Assistive technology in elderly care. Age Ageing 2001:30:455-8.

6 Demiris G, Rantz M, Aud M, Marek K, Tyrer H, Skubic M, et al. Older adults' attitudes towards and perceptions of "smart home" technologies: a pilot study. Med Inform Internet Med 2004;29:87-94.

7 Brownsell S, Hawley MS. Automatic fall detectors and the fear of falling. J Telemed Telecare 2004;10:262-6.
8 Lindemann U, Hock A, Stuber M, Keck W, Becker C. Evaluation of a fall detector based on accelerometers: a pilot study. Med Biol Eng Comput 2005;43:548-51.

9 Roush RE, Teasdale TA, Murphy JN, Kirk MS. Impact of a personal emergency response system on hospital utilization by communityresiding elders. South Med J 1995;88:917-22.

10 Bernstein M. "Low-tech" personal emergency response systems reduce costs and improve outcomes. Manag Care Q 2000;8:38-43.

11 Levine DA, Tideiksaar R. Personal emergency response systems: factors associated with use among older persons. Mt Sinai J Med 1995;62:293-7.

12 Mann WC, Belchior P, Tomita MR, Kemp BJ. Use of personal emergency response systems by older individuals with disabilities. Assist Technol 2005;17:82-8.

13 Fleming J, Zhao E, O'Connor DW, Pollitt PA, Brayne C, CC75C study collaboration. Cohort profile: the Cambridge city over-75s cohort (CC75C). Int J Epidemiol 2007;36:40-6.

14 Fleming J. Patterns and predictors of falls and their consequences in extreme old age. [PhD thesis.] Cambridge: University of Cambridge, 2006.

15 Fleming J, Brayne C, CC75C collaborative. Falls in advanced old age: recalled falls and prospective follow-up of over-90-year-olds in the CC75C study. BMC Geriatrics 2008;8:6.

16 Huppert FA, Brayne C, Gill C, Paykel ES, Beardsall L. CAMCOG-a concise neuropsychological test to assist dementia diagnosis: sociodemographic determinants in an elderly population sample. Br J Clin Psychol 1995;34:529-41.

17 Folstein MF, Folstein SE, McHugh PR. "Mini-mental state". A practical method for grading the cognitive state of patients for the clinician. J Psychiatr Res 1975;12:189-98.

18 Nevitt MC, Cummings SR, Kidd S, Black D. Risk factors for recurrent nonsyncopal falls. A prospective study. JAMA 1989;261:2663-8.

19 Luukinen H, Koski K, Honkanen R, Kivela SL. Incidence of injurycausing falls among older adults by place of residence: a populationbased study. J Am Geriatr Soc 1995;43:871-6.

20 Koski K, Luukinen H, Laippala P, Kivela SL. Risk factors for major injurious falls among the home-dwelling elderly by functional abilities. A prospective population-based study. Gerontology 1998;44:232-8.

21 Lord SR, Ward JA, Williams P, Anstey KJ. An epidemiological study of falls in older community-dwelling women: the Randwick falls and fractures study. Aust J Public Health 1993;17:240-5.

22 Alexander NB, Ulbrich J, Raheja A, Channer D. Rising from the floor in older adults. J Am Geriatr Soc 1997;45:564-9.

23 Asbjornsen G, Braathen L, Mellemstuen H. [Are old patients able to get up from the floor?]. Tidsskr Nor Laegeforen 2000;120:3119-20.

24 Nevitt MC, Cummings SR, Hudes ES. Risk factors for injurious falls: a prospective study. J Gerontol 1991;46:M164-70.

25 King MB, Tinetti ME. Falls in community-dwelling older persons. / Am Geriatr Soc 1995;43:1146-54

26 Reece A, Simpson JM. Teaching elderly people how to cope after a fall. Physiotherapy 1996;82:27-35.

27 Simpson JM, Salkin S. Are elderly people at risk of falling taught how to get up again? Age Ageing 1993;22:294-6.

28 Hofmeyer MR, Alexander NB, Nyquist LV, Medell JL, Koreishi A. Floorrise strategy training in older adults. J Am Geriatr Soc 2002;50:1702-6.

29 Skelton D, Dinan S, Campbell M, Rutherford O. Tailored group exercise (falls management exercise-FaME) reduces falls in community-dwelling older frequent fallers (an RCT). Age Ageing 2005;34:636-9.

30 Shaw FE, Kenny RA. Can falls in patients with dementia be prevented? Age Ageing 1998;27:7-9.

31 Howse K, Ebrahim S, Goober-man Hill R. Help-avoidance: why olde people do not always seek help. Rev Clin Gerontol 2004;14:63-70.

32 Yardley L, Donovan-Hall M, Francis K, Todd C. Older people's views of advice about falls prevention: a qualitative study. Health Educ Res 2006;21:508-17.

33 Yardley L, Bishop FL, Beyer N, Hauer K, Kempen GI, Piot-Ziegler C, et al. Older people's views of falls-prevention interventions in six European countries. Gerontologist 2006;46:650-60.

34 Gill T, Taylor AW, Pengelly A. A population-based survey of factors relating to the prevalence of falls in older people. Gerontology 2005;51:340-5.

35 Berg WP, Alessio HM, Mills EM, Tong C. Circumstances and consequences of falls in independent community-dwelling older adults. Age Ageing 1997;26:261-8.

36 Cameron ID, Quine S. External hip protectors: likely non-compliance among high risk elderly people living in the community. Arch Gerontol Geriatr 1994;19:273-81.

Accepted: 5 September 2008 